\title{
Incorporating the Electrode-Tissue Interface to Cochlear Implant Models
}

\author{
Wei-Dian Lai ${ }^{1}$ and Charles T. M. Choi ${ }^{2}$ \\ ${ }^{1}$ Electrical Engineering Department, I-Shou University, Taiwan, R.O.C. and Computer Science Information Engineering \\ Department, Chung Chou Institute of Technology, Taiwan, R.O.C. \\ ${ }^{2}$ Department of Computer Engineering and Brain Research Center, National Chiao Tung University, Taiwan, ROC
}

\begin{abstract}
The electrode is an important part of cochlear implant system because it affects the current spread and the response of the auditory nerves. In this paper, a new electrode-tissue interface model is coupled with a 3D cochlea and electrode model to simulate the condition of the electrodes in human cochlea is proposed. The effect of incorporating the electrode-tissue interface in a cochlea and the response of the auditory nerves is discussed. Three models are studied, a model of electrode without interface, a model of electrode incorporating the interface effect through an equivalent circuit, and a new model of electrode incorporating a thin layer between the electrode and the scala typmani. The three electrode models were studied using activating functions. Significant different results were found for electrodes with or without taking interface into account. The model results for the electrode model taking into account of the interface effect using an equivalent circuit and a thin interface layer are almost identical.
\end{abstract}

Index Terms-Cochlear implant, computational neuroscience model, electrode-tissue interface, equivalent circuits, interfacial layer, volume conduction method.

\section{INTRODUCTION}

D YMOND [1] studied the characteristics of the metal-tissue interface of stimulation electrodes in 1976. The metal-tissue interface was divided into three adjacent microregions (metal, charge in inner layer, and the charge in diffuse layer). An equivalent circuit of the electrode interface was derived from the physical structure and mechanism as given in Fig. 1. The interfacial impedance of the electrode is a faradaic impedance and a double layer capacitance $\left(\mathrm{C}_{\mathrm{dl}}\right)$ which is in parallel with a faradaic impedance $\left(R_{p}\right)$. $R_{t}$ is the charge-transfer resistance. $Z_{d}$ is the diffusional impedance. $Z_{r}$ is the reaction impedance. Hui et al. [2] utilized the bipolar electrode pairs that were implanted in a cochlea and biphasic current pulse to estimate the impedance of the electrode interface. They used different current density $\left(100-1000 \mathrm{~A} / \mathrm{m}^{2}\right)$ to measure the values of $R_{s}, R_{p}\left(R_{p}=R_{t}+Z_{d}+Z_{r}\right)$ and $\mathrm{C}_{\mathrm{p}}\left(\mathrm{C}_{\mathrm{p}}=\mathrm{C}_{\mathrm{dl}}\right)$. They discovered that there is no consistent variation in the stimulation current with $R_{s}$, but $R_{p}$ and $C_{p}$ are dependent on the current. Tykocinski et al. [3] studied the chronic electrical stimulation of the auditory nerves. They used the same current stimulus $(0.5 \mathrm{~mA}, 50 \mu \mathrm{s} / \mathrm{phase}$ charge-balanced biphasic current pulses) to compute the access resistance, $\left(R_{a}, R_{a}=R_{s}\right)$ and the polarization impedance $\left(\mathrm{Z}_{\mathrm{pol}}, \mathrm{Z}_{\mathrm{pol}}=\mathrm{R}_{\mathrm{p}} / / \mathrm{C}_{\mathrm{p}}\right)$. While the electrode-tissue interface was studied [1]-[3], it has never been studied in conjunction with any finite element model. The primary aim of this paper is to propose a new tissue-electrode model which includes a thin layer between the electrode and the scala tympani to incorporate the effect of the electrode- tissue interface to our cochlear implant computer model and improve the accuracy of the analysis of the electrically stimulated cochlea. Since

Digital Object Identifier 10.1109/TMAG.2007.892504

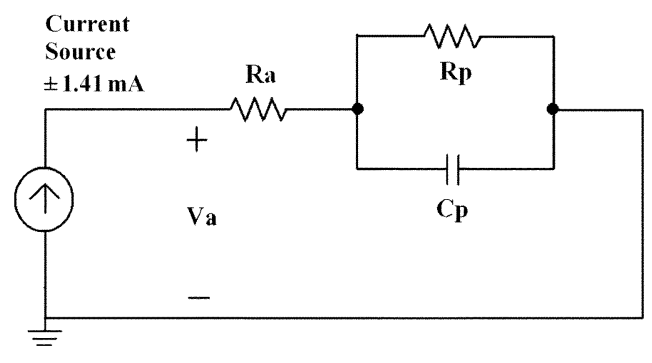

Fig. 1. The equivalent circuit of an electrode interface. Va is the source voltage.

the Scala Tympani is mainly conductive and not capacitive, a complex permittivity is not required in that region [4]. The result generated from this new model will be compared with the result from the electrode model without taking into account of the interface and an equivalent circuits model to represent the effect of the interface [2], [3]. The secondary goal of this paper is to compare the three models in terms of activating function to find out how do the electrodes with or without interface affects the excitation pattern of the auditory nerves.

\section{THEORY AND METHOD}

The definitions of interfacial layer and electrode are shown in Fig. 2. Since the size of the real interfacial layer is too thin to implement in the cochlear models, a more manageable thickness of $0.05 \mathrm{~mm}$ is used in all three cases. In Fig. 2(a), the capacitance of a planar electrode with an interfacial layer is calculated from

$$
\mathrm{C}=\varepsilon \frac{\mathrm{A}}{\mathrm{d}} .
$$

where $\mathrm{C}$ is capacitance $(\mathrm{F}), \varepsilon$ is complex permittivity, A represents cross section area of the electrode $\left(\mathrm{m}^{2}\right)$, and $\mathrm{d}$ is the distance between the two electrodes (m). Fig. 2(b) shows a half banded electrode with interfacial layer. Fig. 2(c) shows a banded electrode with interfacial layer. The capacitance of half banded 


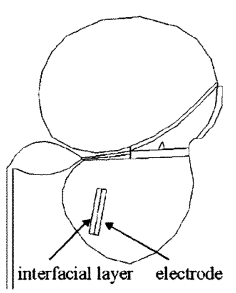

(a)

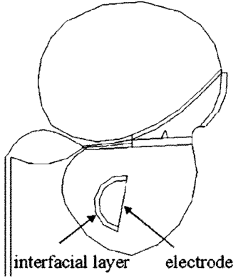

(b)

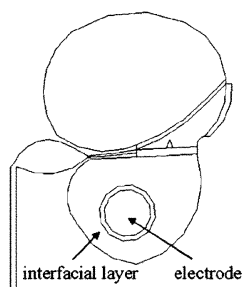

(c)
Fig. 2. Three interfacial layers and electrodes configurations: (a) planar electrode, (b) half banded electrode, and (c) banded electrode.

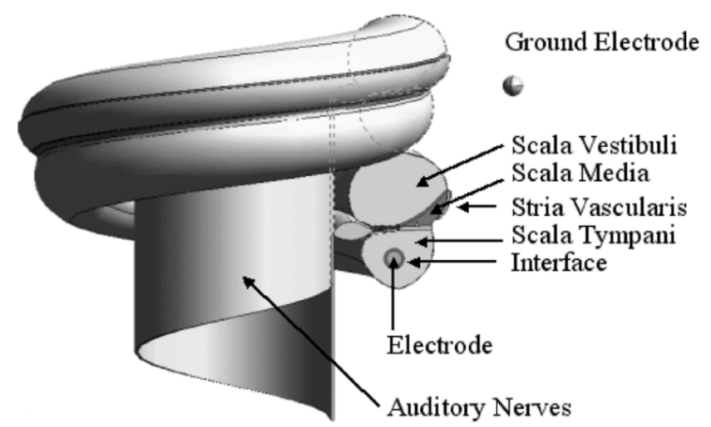

Fig. 3. The finite element model of cochlea and the electrodes. The small circle in the outside is the external ground electrode.

electrode is half of the value of the banded electrode, but its resistance value is twice that of the banded electrode. An equivalent circuit [3], based on Ohm's law, is used to compute the access resistance, $R_{a}$, the resistance between two electrodes in our cochlea model (Fig. 3). In this paper, the monopolar configuration (the active electrode is within the cochlea and the return electrode is external to the cochlea) is modeled to simulate the change of the potential in time when the interface model is added to the electrodes. In the proposed scheme, the finite element method is applied to simulate the access resistance $\left(R_{a}\right)$ and polarization impedance $\left(Z_{p}\right)$, adopting the polarization impedance data from [2]. In the circuit approach to model the electrode-tissue interface effect, with an input as shown in Fig. 4, the cochlea equivalent circuit $\left(R_{a}\right)$ and the electrode-tissue interface circuit $\left(\mathrm{Z}_{\mathrm{p}}\right)$ were modeled with SPICE and compared with the circuit model without the interface $\left(Z_{p}\right)$ in Fig. 5. Fig. 5 shows a significant distortion of the electrical potential with the electrode-tissue interface circuit. As a result, it should generate a significant change in the neural excitation pattern [5]-[7] with the interface incorporated. Since it is difficult to study the neural excitation pattern using the circuit approach only, the proposed interface scheme should improve the modeling accuracy of the finite element model of the cochlea prosthesis system [5]-[7].

\section{RESULT}

Fig. 3 shows a 3-D circular cochlea model, which includes the Basilar membrane (4 $\Omega-\mathrm{M})$, Reissner's membrane (340.13 $\Omega$-M), scala tympani (0.7 $\Omega$-M), scala vestibuli $(0.7 \Omega-\mathrm{M})$, scala media $(0.6 \Omega-\mathrm{M})$, spiral ganglion $(3 \Omega-\mathrm{M})$, bone $(6.41$ $\Omega-\mathrm{M}$ ), peripheral axonal process (axial direction $=3 \Omega-\mathrm{M}$; transverse direction $=15 \Omega-\mathrm{M})$, and the stria vascularis $(125.79 \Omega-\mathrm{M})$, were studied by incorporating their resistivities [6]. Three electrode models were studied: the first electrode

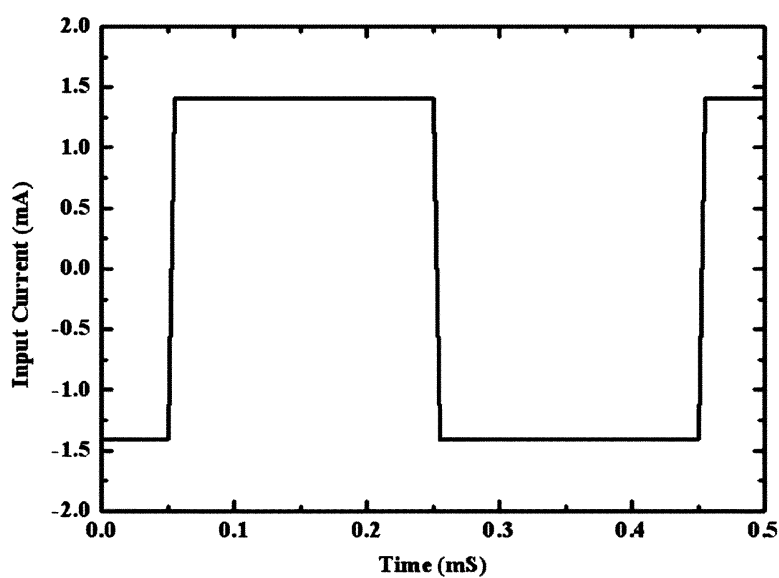

Fig. 4. The input current driving the electrode is $\pm 1.41 \mathrm{~mA}, 0.2 \mathrm{mS} / \mathrm{pulse}$ width.

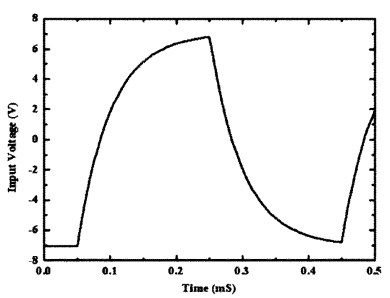

(a)

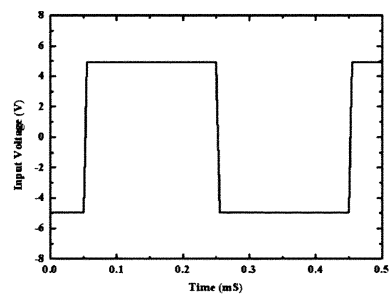

(b)
Fig. 5. The input current driving the electrode is $\pm 1.41 \mathrm{~mA}$ and $0.2 \mathrm{mS} /$ pulse width. (a) The voltage between the electrodes adding the effect of the interface of the electrode. The RC exponential growth and decay are clearly seen due to addition of the electrode-interface model. (b) The voltage between the electrodes without the effect of the interface of the electrode.

model does not take into account of any interface effect; the second electrode model takes into account of the effect of the interface by an equivalent circuits (Fig. 1); the third model incorporates a thin layer between the electrode and the scala tympani. The layer is $0.5 \mathrm{~mm}$ thick and a complex permittivity is imposed in the layer. The complex permittivity is based on a $\mathrm{R}_{\mathrm{p}}$ of $5 \mathrm{k} \Omega$ and $\mathrm{C}_{\mathrm{p}}$ of $10 \mathrm{nF}$ [2] calculated using Ohm's law and simple capacitor equations (Table I). The inputs of all three cases are a constant current at $\pm 1.41 \mathrm{~mA}$ as shown in Figs. 1 and 4. An activating function [5] is used to obtain an impression of the excitation pattern of the electrical stimulation. AF can be computed from the nerve fiber nodes given in Fig. 6.

The results of the first model which does not take into account of the interfacial effect are shown in Figs. 7 and 8. The peak activation function (AF) in the AF contour [5] is a measure of how likely is the auditory nerve fibers would be excited by the electrode for a given power input. The higher of the AF value is the meaning likely the auditory nerves being excited [5]. Fig. 7 (a) shows a peak absolute AF value of $19.5104 \times 10^{6} \mathrm{v} / \mathrm{mm}^{2}$ for planar electrode. Fig. 7(b) shows the peak absolute AF value of $15.3143 \times 10^{6} \mathrm{v} / \mathrm{mm}^{2}$ for half banded electrodes. Banded electrode generates absolute peak AF value of $10.1176 \times 10^{6}$ $\mathrm{v} / \mathrm{mm}^{2}$ in Fig. 8(a). Fig. 8(b) shows the absolute peak value of AF of $3.1415 \times 10^{6} \mathrm{v} / \mathrm{mm}^{2}$ for ball electrodes.

Fig. 7 to 8 show the planar electrode stimulates more efficiently than the other three electrodes, which is consistent with the published results [7]. The second model incorporates the effect of the interface by an equivalent circuit [2], [3] 
TABLE I

PARAMETERS FOR THE Finite ELEMENT MODEL With AND Without INTERFACIAL LAYERS, THE EQUIVALENT CIRCUIT MODEL, THOSE PUBLISHED FROM THE LITERATURE [2], [3]

\begin{tabular}{|c|c|c|c|c|c|c|}
\hline & \begin{tabular}{c|} 
Input \\
Current
\end{tabular} & $\begin{array}{c}\text { Input } \\
\text { Voltage }\end{array}$ & $\mathbf{R a}$ & $\mathbf{R p}$ & Cp & AF value \\
\hline Paper & $\pm 1.41 \mathrm{~mA}$ & $\pm 11.98 \mathrm{~V}$ & $3500 \Omega$ & $5000 \Omega$ & $10 \mathrm{nF}$ & \\
\hline \multicolumn{7}{|c|}{ No Interfacial layer } \\
\hline Planar & $\pm 1.41 \mathrm{~mA}$ & $\pm 7.92 \mathrm{~V}$ & $5658.37 \Omega$ & & & $\begin{array}{c}19.5104 \times 10^{6} \\
\mathrm{v} / \mathrm{mm}^{2}\end{array}$ \\
\hline $\begin{array}{c}\text { Half } \\
\text { banded }\end{array}$ & $\pm 1.41 \mathrm{~mA}$ & $\pm 7.03 \mathrm{~V}$ & $5556.66 \Omega$ & & & $\begin{array}{c}15.3144 \times 10^{6} \\
\mathrm{v} / \mathrm{mm}^{2}\end{array}$ \\
\hline Banded & $\pm 1.41 \mathrm{~mA}$ & $\pm 6.09 \mathrm{~V}$ & $5504.46 \Omega$ & & & $\begin{array}{c}10.1176 \times 10^{6} \\
\mathrm{v} / \mathrm{mm}^{2}\end{array}$ \\
\hline \multicolumn{7}{|c|}{ Equivalent Circuit } \\
\hline Planar & $\pm 1.41 \mathrm{~mA}$ & $\pm 26.14 \mathrm{~V}$ & $5618.62 \Omega$ & $12923.29 \Omega$ & $3.87 \mathrm{nF}$ & \\
\hline $\begin{array}{c}\text { Half } \\
\text { banded }\end{array}$ & $\pm 1.41 \mathrm{~mA}$ & $\pm 17.26 \mathrm{~V}$ & $4985.89 \Omega$ & $7500 \Omega$ & $6.67 \mathrm{nF}$ & \\
\hline Banded & $\pm 1.41 \mathrm{~mA}$ & $\pm 11.21 \mathrm{~V}$ & $4316.66 \Omega$ & $3750 \Omega$ & $13.33 \mathrm{nF}$ & \\
\hline \multicolumn{7}{|c|}{ With Interfacial layer } \\
\hline Planar & $\pm 1.41 \mathrm{~mA}$ & $\pm 26.14 \mathrm{~V}$ & $5618.62 \Omega$ & $12923.29 \Omega$ & $3.87 \mathrm{nF}$ & $\begin{array}{c}20.0293 \times 10^{6} \\
\mathrm{v} / \mathrm{mm}^{2} \\
\end{array}$ \\
\hline $\begin{array}{c}\text { Half } \\
\text { banded }\end{array}$ & $\pm 1.41 \mathrm{~mA}$ & $\pm 17.26 \mathrm{~V}$ & $4985.89 \Omega$ & $7500 \Omega$ & $6.67 \mathrm{nF}$ & $\begin{array}{c}19.5081 \times 10^{6} \\
\mathrm{v} / \mathrm{mm}^{2}\end{array}$ \\
\hline Banded & $\pm 1.41 \mathrm{~mA}$ & $\pm 11.21 \mathrm{~V}$ & $4316.66 \Omega$ & $3750 \Omega$ & $13.33 \mathrm{nF}$ & $\begin{array}{c}18.0899 \times 10^{6} \\
\mathrm{v} / \mathrm{mm}^{2}\end{array}$ \\
\hline
\end{tabular}

Resistivities $=51.69321113 \Omega-\mathrm{M}$, Permittivity $=109243.95$, Interfacial layer thickness $=0.05 \mathrm{~mm}$

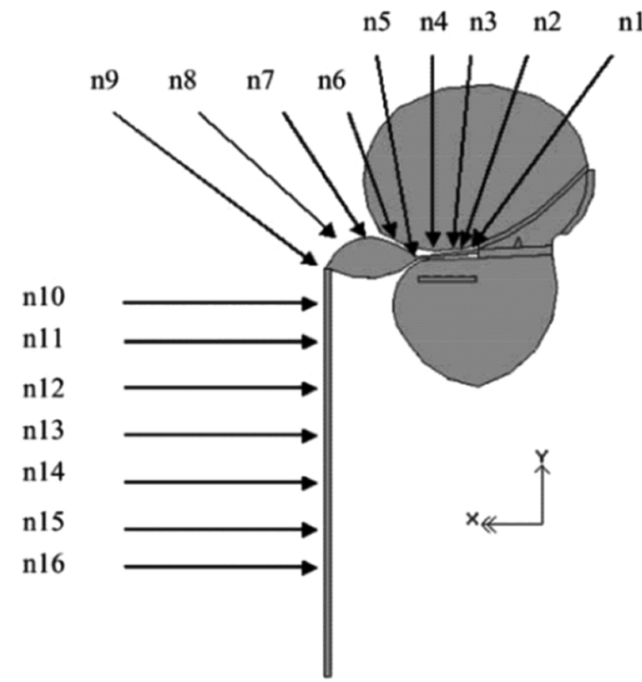

Fig. 6. A two-dimensional cross section of a cochlea model. The nerve fiber nodes used for computation of the activating function contour are n1-n16 (Figs. $7,8$, and $10-12)$

The $R_{p}$ used is equal to $5 \mathrm{k} \Omega$ and $C_{p}$ used is $10 \mathrm{nF}$ [2]. The serial resistance $\left(\mathrm{R}_{\mathrm{a}}\right)$ used is calculated from the finite element model (Fig. 2). The $R_{a}$ value for the planar electrodes is $5658.37 \Omega$, the $R_{\mathrm{a}}$ value of half banded electrodes is 5556.66 $\Omega$, the $R_{a}$ value of banded electrodes is $5504.46 \Omega$. Since it is not possible to generate an $\mathrm{AF}$ contour for this case, we will compare the potential across the electrode $\left(\mathrm{V}_{\mathrm{a}}\right.$ in Fig. 1) with the next model later.

Next, we consider the third method, which is a new method proposes in this paper. We used the same $R a, R_{p}$, and $C_{p}$ values of the interface, but realized not through a circuit as

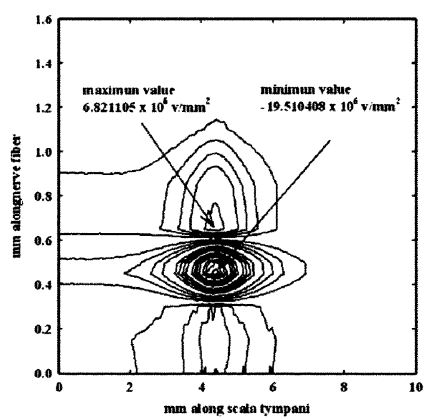

(a)

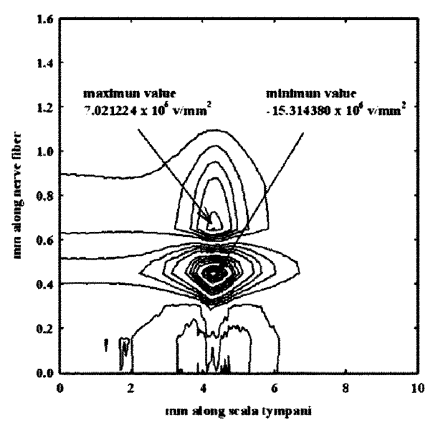

(b)
Fig. 7. (a) AF contour of a planar electrode without interfacial layer. (b) AF contour of a half banded electrode without interfacial layer.

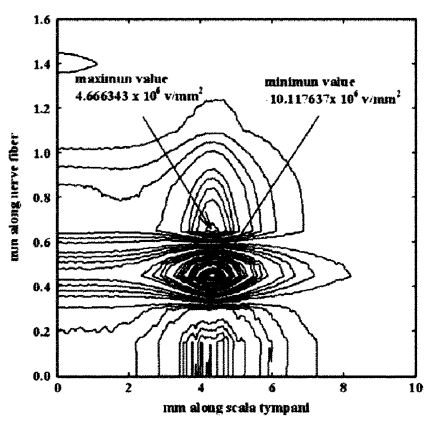

(a)

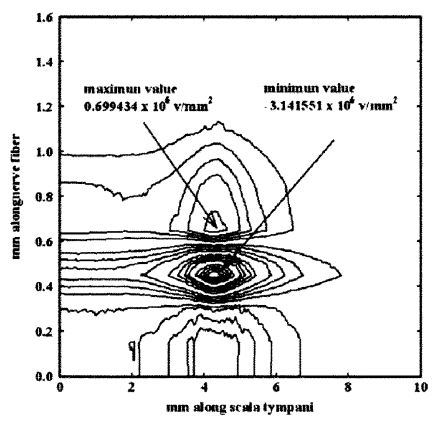

(b)
Fig. 8. (a) AF contour of a banded electrode without interfacial layer. (b) AF contour of a ball electrode without interfacial layer.

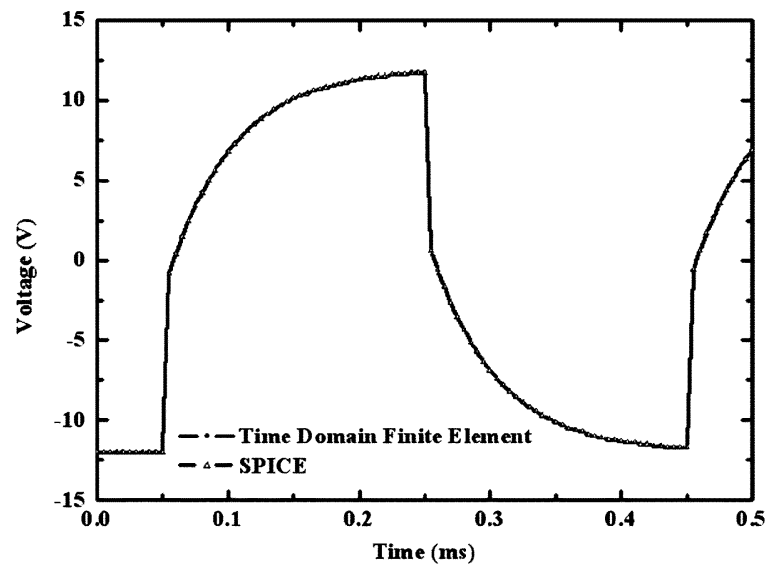

Fig. 9. Electrode potential comparison for the equivalent circuit approach (SPICE) and the proposed complex parameters thin layer approach (Time domain finite element method). The potential are almost identical for both approaches, which validate the proposed method.

in the second method, but in a thin layer with a complex permittivity. By imposing the complex permittivity values in the interface layer geometrically located between the electrodes and the scala tympani, it is possible to generate the effect of a tissue-electrode interface. Fig. 9 shows a comparison of potential between the electrodes for case two, which is $V_{a}$ in Fig. 1, with the potential between the electrodes in the third case, which uses a time domain finite element method to solve the Possion's equation. The results show that they are almost identical to each other, which validate the proposed thin layer approach to model the tissue-electrode interface. Next, we 


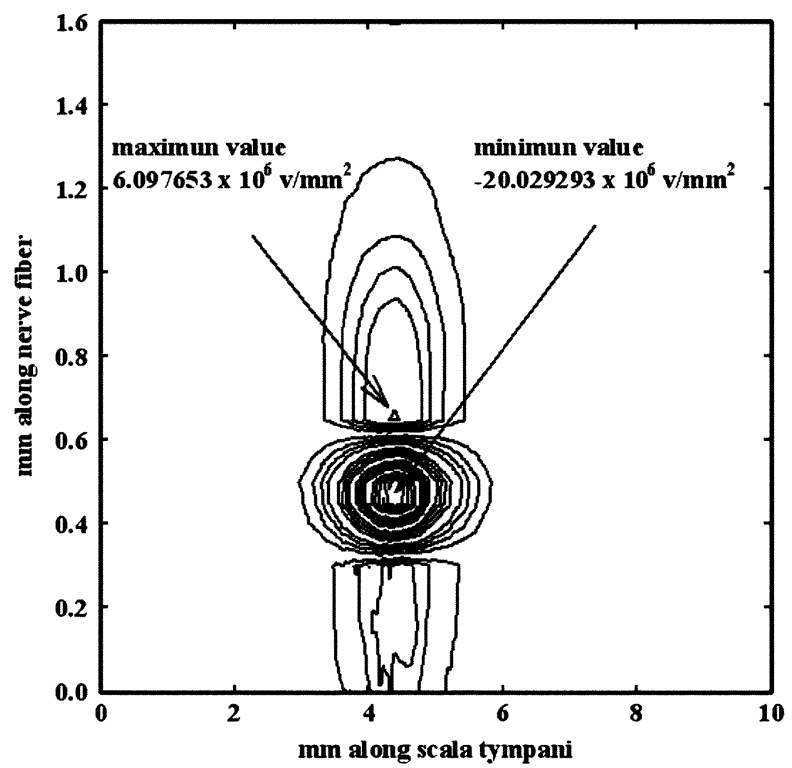

Fig. 10. AF contour of a planar electrode with thin layer interface model. The interface is realized through a thin layer with a complex permittivity.

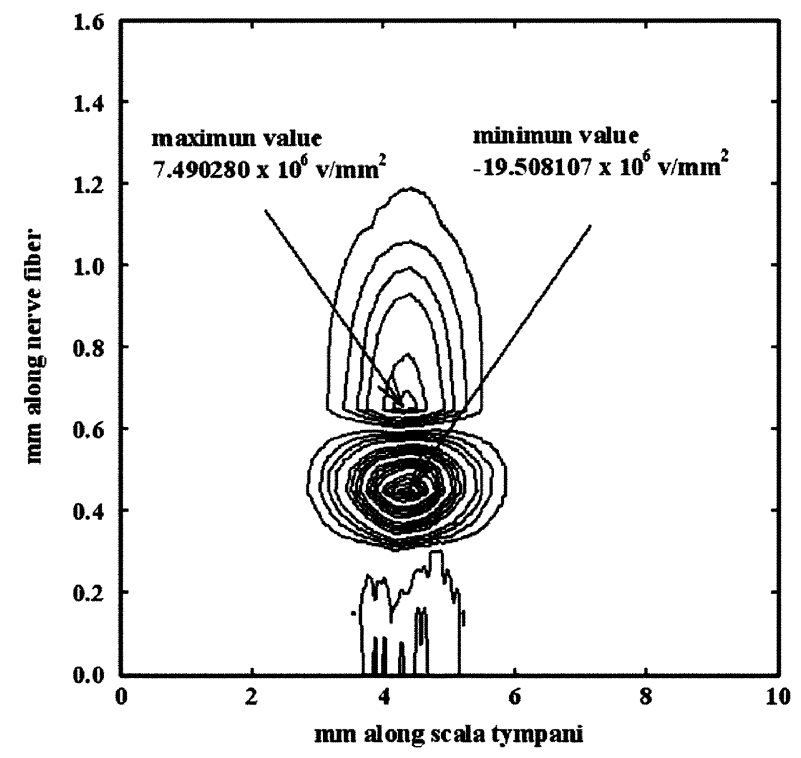

Fig. 11. AF contour of a half banded electrode with a thin layer interface model.

computed the AF contour for the model for the third case as in the previous figures. Figs. 10-12 show the AF contours of the new method. The peak absolute AF values are $20.0292 \times 10^{6}$ $\mathrm{v} / \mathrm{mm}^{2}, 19.5081 \times 10^{6} \mathrm{v} / \mathrm{mm}^{2}$, and $18.0898 \times 10^{6} \mathrm{v} / \mathrm{mm}^{2}$ for planar electrodes, half banded electrodes, and banded electrodes, respectively. Table I shows that the proposed thin layer complex parameter approach matches the parameters from the equivalent circuit approach quite nicely. It also shows that the AF contour changes significantly with or without the interface.

\section{CONCLUSION}

This paper presents a new method of incorporating the electrode-tissue interface in the finite element model. The resultant time domain potential plot shows that they are essentially the

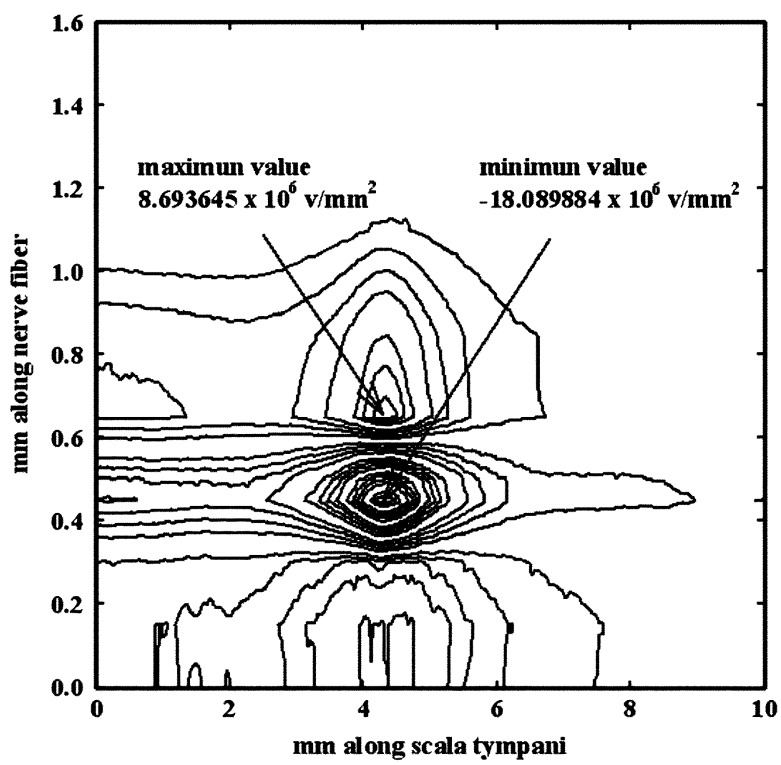

Fig. 12. AF contour of a banded electrode with thin layer interface model.

same as the equivalent circuit model published previously. This method allows more flexibility in the design because it took the circuit out of the model. This paper also presents a comparison of the neural excitation pattern of four electrode models with or without taking into account of the electrode-tissue interface effect. With the interfaces, the electrodes are more likely to excite the auditory nerve fibers at higher frequency.

\section{ACKNOWLEDGMENT}

This work was supported in part by the NSC under Research Grant NSC 94-2213-E-214-048.

\section{REFERENCES}

[1] A. M. Dymond, "Characteristics of the metal-tissue interface of stimulation electrodes," IEEE Trans. Biomed. Eng., vol. 23, no. 7, pp. 274-280, Jul. 1976.

[2] H. L. Hui, J. M. Hugh, C. T. Yit, and W. Ross, "Approximation Of intracochlear electrode impedance from telemetered measurements in a multi-electrode cochlear implant patient," in Proc. IEEE Medicine and Biology Society Conf., 1990, pp. 2288-2289.

[3] M. Tykocinski, Y. Duan, B. Tabor, and R. S. Cowan, "Chronic electrical stimulation of the auditory nerve using high surface area (HiQ) platinum electrodes," Hear. Res., vol. 159, pp. 53-68, 2001.

[4] T. Hanekom, "Modelling of the Electrode-Auditory Nerve Fiber Interface in Cochlear Prostheses," Ph.D. Dissertation, Faculty of Engineering, Built Environment and Information Technology, Univ. Pretoria, Pretoria, South Africa, Jun. 2001.

[5] C. T. M. Choi, W.-D. Lai, and Y. B. Chen, "Optimization of cochlear implant electrode array using genetic algorithms and computational neuroscience models," IEEE Trans. Magn., vol. 40, no. 2, pp. 639-642, Mar. 2004.

[6] J. H. M. Frijns, S. L. de Snoo, and R. Schoonhoven, "Potential distributions and neural excitation patterns in a rotationally symmetric model of the electrically stimulated cochlea," In Frijns, J. H. M., Cochlear Implants. A Modelliing Approach, pp. 93-124, 1995, Den Haag: CIP-Data Koninklijke Bibliotheek.

[7] C. T. M. Choi, W.-D. Lai, and Y. B. Chen, "Comparison of electrical stimulation performance of four cochlear implant electrodes," IEEE Trans. Magn., vol. 41, no. 5, pp. 1920-1923, May 2005.

Manuscript received April 26, 2006 (e-mail: c.t.choi@ieee.org; ctchoi@cs. nctu.edu.tw). 